\title{
Reviewing the National Sexual Health and HIV Strategy
}

\author{
Susan Mann, Christopher Wilkinson
}

\section{Background}

The English National Strategy for Sexual Heath and HIV $(2001)^{1}$ was a landmark in raising sexual health as a national issue. The Sexual Health Independent Advisory Group commissioned a review of the strategy's progress, Progress and Priorities - Working Together for High Quality Sexual Health, ${ }^{2}$ which was published in July 2008. The review highlights the need to build on what has been done to maintain the profile for sexual health through local and national leadership, effective partnerships across health and social care, effective commissioning, prevention and further modernisation of service delivery. Importantly, it clearly raises the profile of contraception and abortion as priorities in sexual health care. In this commentary we aim to summarise some of the main issues presented in relation to contraceptive service provision in the review.

\section{Progress in sexual health}

The original strategy attempted to straddle the range of issues relating to sexual and reproductive health care (SRH) and HIV. It was an important lever for placing sexual health on a national agenda, further strengthened by the government White Paper, Choosing Health. ${ }^{3}$ The introduction of national targets for a reduction in the number of conceptions in under-18-year-olds, 48-hour access to genitourinary medicine (GUM) services and increasing access to abortion before 10 weeks became a major driver for achievements in these areas of sexual health. We have seen teenage conception rates decrease by $13.3 \%$ from baseline, $98.9 \%$ of GUM appointments are offered within 48 hours of contacting the service, ${ }^{4}$ and access to abortion within 10 weeks has increased from $51 \%$ to $68 \% .5$ We now have an English Chlamydia Screening Programme, and although to date only two primary care trusts (PCTs) have achieved the $15 \%$ target for proportion of the population screened, all have a functioning programme.

However, lack of detailed attention to contraception and abortion in the original document, compounded by a lack of contraception-specific targets, left this area without a route map for service development. In addition, funds pledged to support the implementation of Choosing Health did not find their way directly into services as promised, ${ }^{6}$ and disinvestments resulted in service closures as contraception failed to take its place in local priority setting. 7,8

\section{Need for contraception}

Delays in childbearing and a shifting population age structure have meant that while the rate of increase in conceptions is an issue across all reproductive ages, it has been greatest in the over 40-year-old age group. Unmet

J Fam Plann Reprod Health Care 2008; 34(4): 211-212

Contraceptive and Reproductive Health Services, Margaret Pyke Centre, London, UK

Susan Mann, MBChB, MSRH, Specialist Registrar in Public Health Medicine and Research Associate in Sexual and Reproductive Health

Christopher Wilkinson, MBBS, FFSRH, Consultant in Sexual and Reproductive Healthcare and Sexual and Reproductive Health Lead, London Sexual Health Programme, London, UK

Correspondence to: Dr Susan Mann, Contraceptive and Reproductive Health Services, Margaret Pyke Centre,

73 Charlotte Street, London W1P 1LB, UK.

E-mail: suemann@doctors.org.uk need for contraception is seen clearly through rising abortion rates across all age groups. In spite of the fact that $85 \%$ of people of childbearing age report using contraception, ${ }^{9}$ there appears to be a wide discrepancy between these perceptions and effective use.

The strategy review clearly identifies the need to prioritise community contraceptive services. Nonetheless, ensuring that this is translated into effective action will be a major challenge in the face of rising unmet need for contraception, changing National Health Service (NHS) policy and structure, as well as technological advance and behavioural change.

\section{Changing policy landscape}

Since 2001 there have been substantial developments in health policy. From April 2008, a statutory duty was placed on local authorities alongside PCTs to carry out a Joint Strategic Needs Assessment, ${ }^{10}$ the results of which will be used to inform Local Area Agreements, forming the basis of joint local health strategy. While partnership working has been central to the Teenage Pregnancy Strategy, this has been less comprehensively explored within other areas of sexual health, and it is imperative for the health sector to engage more meaningfully if it is to sustain levels of local priority. Given a lack of contraception-specific targets this is particularly pertinent. There is a need to highlight the essential role of services in contributing to achievement of sexual health targets within local strategic partnerships. Equally - as recommended by the review - there is a need to identify and explore links with other areas of health improvement that might hold priority within local health strategy such as drug and alcohol use and high-risk sexual behaviour.

Policy has shifted towards placing clients at the centre of their care and to increasing convenience and accessibility by shifting care out of hospitals into the community. The value of prevention is also increasingly recognised. SRH is uniquely placed as a specialty within the community and with a purpose in prevention, compliant with the new closer-to-home, client-focused, holistic agenda. However, while this presents an opportunity, PCTs have consistently failed to prioritise sexual health prevention in their resource allocation processes.

\section{Commissioning and market reforms}

Payment by results (PbR) was intended to promote competition, increase activity and improve quality. $\mathrm{PbR}$ tariffs are available for GUM and hospital abortions, but not for other elements of sexual health care. The abortion tariff excludes post-abortion contraception and preabortion assessment, disassociating abortion from contraceptive care. The strategy review recommends that $\mathrm{PbR}$ be implemented more widely. Based on reference costs, the GUM tariffs are crude, poorly implemented and hinder the provision of holistic sexual health care. Whilst there are examples of local tariffs being developed, as a result of a lack of prioritisation it is unlikely that a national tariff will be in place before 2010, and this has an impact on the ability to de-host. The Department of Health should ensure the development of meaningful tariffs that apply across both acute and community providers. However, this delay does give providers time to review their information technology infrastructure to ensure readiness for this system of financing. 
Leadership and levels of public health and commissioning expertise across sexual health are variable. Many PCTs have not had sexual health leads or commissioners with sufficient time, experience or authority. Driving the strategy forward is often left to committed local champions who are key, but who should not have to function in isolation. PCTs must ensure that commissioning, public health and provider networks are supported to ensure local implementation of the strategy.

Many commissioners have not appreciated the breadth of care and the role of community services in the provision of training, clinical governance, specialist care and access for harder-to-reach groups. Offering a range of elements of sexual health care, community services play an important part in achieving national targets such as chlamydia screening, cervical screening, abortion referrals and 48hour GUM access; and would be important for a contraceptive target were it to be introduced. ${ }^{6}$

\section{Service delivery}

There is a lack of consistency in the contraceptive advice that clients receive at the point of access, and often a lack of knowledge at PCT level about what is actually being provided. Market reforms have resulted in the creation of a wider range of potential service providers where quality can vary and competition may supersede collaboration. Strategic planning is required to ensure that the configuration of services commissioned reflects need, ensures high quality and allows individual clients to move seamlessly within networks. Today's commissioners require expertise to ensure that services are placed in the hands of providers able to deliver high-quality services to required outcomes. This includes the recognition of training needs to ensure that the workforce is competent to deliver the full range of services. To increase access to Level 1 and long-acting reversible contraception (LARC) ${ }^{11}$ training for non-specialist doctors the theory component of the Diploma of the Faculty of Sexual and Reproductive Healthcare (DFSRH) is being developed in an online format. For nurses, however, in spite of role expansion with more specialist nurses trained in sexually transmitted infection (STI) management and insertion of both implants and intrauterine devices, achievement of a training standard has been slower and should be a priority, utilising established programmes such as the DFSRH.

General practitioners (GPs) provide $80 \%$ of nonspecialist contraceptive care, although only one-third of GPs are currently able to offer the full range of contraceptive choice including LARC. ${ }^{12}$ There is a lack of incentive through the Quality and Outcomes Framework for GPs to provide non-essential sexual health services; this needs addressing to encourage increased provision of LARC and STI management in general practice. Local Enhanced Service agreements are being increasingly explored and bring training requirements, service specification and auditable service standards within the contract. However, there is still wide variation and an ongoing lack of consensus as to whether all GPs should be required to deliver a basic minimum service and what this should comprise, or whether this should be left in the hands of a smaller number of interested GPs and practice nurses complemented by provision across a geographical network of specialist providers.

Pharmacists are the main provider of condoms and emergency contraception and the new pharmacy White Paper, Pharmacy in England - Building on Strengths, Delivering the Future, ${ }^{13}$ signals an increasing role for pharmacists in the provision of basic-level sexual health services. This complies with the demedicalisation agenda and as yet has been not fully exploited, particularly in STI testing and access to abortion.

\section{Research}

In parallel with service developments, expansion and wider dissemination of the evidence base in contraception and abortion is also needed. The original strategy focused almost entirely on increasing research outputs for STIs and HIV, and the majority of the funded studies that followed reflected this emphasis. In addition, there has been no academic career structure for clinicians in SRH, which leaves the specialty heavily reliant on service-based input for development of its evidence base and research needs. A change in focus of the strategy and recognition of the specialty of SRH will bring with it new opportunities for developments in academic training.

\section{Moving forward}

Now is a time of unprecedented change in the NHS and for sexual and reproductive health care. The focus is shifting further towards improving service user experience and choice, and more investment in health and well-being, with stronger commissioning of services. The sexual health strategy channelled energy and progress into sexual health that had not previously been seen and much has been achieved. The recent strategy review ${ }^{2}$ highlights the need to now focus on those areas that were less well addressed previously such as contraception. This national recognition of the importance of contraceptive care is significant; however, making the revised national strategy lead to change that benefits users will be as much about getting contraception and abortion onto local agendas and about local service innovation as any greater national drive.

Statements on funding and competing interests

Funding None identified.

Competing interests None identified.

References

1 Department of Health. Better Prevention, Better Services, Better Sexual Health - The National Strategy for Sexual Health and HIV. London, UK: Department of Health, 2001.

2 Medical Foundation for AIDS \& Sexual Health (MedFASH) for the Independent Advisory Group on Seuxal Health and HIV. Progress and Priorities - Working Together for High Quality Sexual Health. Review of the National Strategy for Sexual Health and HIV. London, UK, Department of Health, 2008.

3 Department of Health. Choosing Health: Making Healthier Choices Easier. London, UK: Department of Health, 2004.

4 Department of Health. The Quarter: quarter 4 (2007-08). London, UK: Department of Health, 2008.

5 Department of Health. Abortion Statistics, England and Wales: 2006. London, UK: Department of Health, 2007

6 Kishen M, Belfield T. Contraception in crisis. J Fam Plann Reprod Health Care 2006; 32: 211-212.

7 Brook, fpa, Medical Foundation for AIDS \& Sexual Health (MedFASH), National AIDS Trust (NAT) and Terrence Higgins Trust (THT). Review of Primary Care Trust Local Delivery Plans (2005-2008). 2006. http://www.nat.org.uk/document/9 [Accessed 12 August 2008]

8 Terence Higgins Trust. Disturbing Symptoms 5 (How Primary Care Trusts Managed Sexual Health and HIV in 2006 and How Specialist Clinicians Viewed Their Progress). London, UK: Terence Higgins Trust, 2007.

9 Office for National Statistics. Contraception and Sexual Health 2006/07 (Omnibus Survey Report No. 33). London, UK: Office for National Statistics, 2007

10 Department of Health. Joint Strategic Needs Assessment London, UK: Department of Health, 2007

11 Wilkinson C, Mavranezouli I. Long-acting reversible contraceptives: not only effective, but also a cost-effective option for the National Health Service. J Fam Plann Reprod Health 2006: 32: 3-5.

12 All Party Parliamentary Pro-Choice and Sexual Health Group. A Report into the Delivery of Sexual Health Services in General Practice. London, UK: fpa, October 2007.

13 Department of Health. Pharmacy in England - Building on Strengths, Delivering the Future. London, UK: Department of Health, 2008. 